\title{
The hydrochemical characteristics and quality assessment of groundwater in Shuangliao City, China
}

\author{
Mingjun Liu ${ }^{1}$, Changlai Xiao ${ }^{1, *}$, and Xiujuan Liang ${ }^{1}$ \\ ${ }^{1}$ Key Laboratory of Groundwater Resources and Environment, Ministry of Education, and National- \\ Local Joint Engineering Laboratory of In-situ Conversion, Drilling and Exploitation Technology for \\ Oil Shale, and College of New Energy and Environment, Jilin University, No 2519, Jiefang Road, \\ Changchun 130021, PR China
}

\begin{abstract}
In this study, a hydrochemical investigation was conducted in Shuangliao city to identify the hydrochemical characteristics and the quality of groundwater using descriptive statistics and correlation matrices. And on that basis, combined with Analytic hierarchy process (AHP), an improved two-level fuzzy comprehensive evaluation method is used to evaluate the groundwater quality. The results indicate that the major cations and anions in groundwater are $\mathrm{Ca}^{2+}$ and $\mathrm{HCO}_{3}{ }^{-}$, respectively. The chemical types are mainly $\mathrm{HCO}_{3}-\mathrm{Ca}$ type water, some areas are complicated due to the influence of human activities. The evaluation results show that the water quality in the area is mostly III type water, and the groundwater quality in some areas is IV or V water due to the influence of primary geological conditions or human activities. The groundwater quality in the East Liaohe River Valley and Shuangliao urban area is relatively poor, and in the northwest part which is the saline alkali soil area is also relatively poor.
\end{abstract}

\section{Introduction}

The chemical composition of groundwater is related to the environment in which it exists, and the change of its chemical composition is caused by the interaction between groundwater and its surrounding environment [1]. The chemistry of groundwater in an area can show that the groundwater in this area evolves over time. The existence of human beings can not be separated from reliable groundwater resources. The groundwater quality directly affects the function of water supply and has a bearing on the vital interests of the people [2-7]. Therefore, understanding the groundwater characteristics is crucial for groundwater resources management in the study area.

Shuangliao city with an area of $2887 \mathrm{~km}^{2}$, is located at the junction of Jilin, Inner Mongolia and Liaoning provinces in northeast China, belonging to Siping city of Jilin province, between $123^{\circ} 20^{\prime}$ to $124^{\circ} 05^{\prime} \mathrm{E}$ longitude and $43^{\circ} 20^{\prime}$ to $44^{\circ} 05^{\prime} \mathrm{N}$

\footnotetext{
* Corresponding author: xcl2822@126.com
} 
latitude. The study area is characterized as a semi-arid and semi-humid transitional zone with windy spring, with an annual mean precipitation of $450-550 \mathrm{~mm}$, an annual mean evaporation above $1600 \mathrm{~mm}$, and annual mean temperature of $5.6{ }^{\circ} \mathrm{C}$. The temperature varies greatly with an average temperature in January being about $-15{ }^{\circ} \mathrm{C}$ and in July is $23{ }^{\circ} \mathrm{C}$.

The main rivers in the region are the East Liaohe River, the West Liaohe River and the Xinkai River. Topographically, the east is higher than the west and the south is higher than the north. There are more saline-alkali soils in the study area. The area is distributed widely Quaternary strata with only five Neogene basalt volcanic cones.

\section{Materials and methods}

\subsection{Data sources}

The chemical data of groundwater in Shuangliao City were collected by the project group from 1983 to 1985,1988 to 1989 and 1992 to 2005. The analysis indexes include major components and trace elements, and the groundwater were withdraw form unconfined aquifer.

\subsection{Two-level fuzzy comprehensive evaluation method}

The fuzzy comprehensive evaluation method is used to describe the fuzzy grading boundary of water quality by the degree of membership. This method not only recognizes the "one or the other" relationship of things to a certain category, but also emphasizes the fuzziness of the objective existence of "intermediate transition" in a certain category. Therefore, it can accurately depict the objective existence of water quality and obtain a practical evaluation effect [8]. The first-order fuzzy comprehensive evaluation function is obtained by taking the average, the maximum, the minimum, etc. These methods have a certain amount of one-sidedness, or over-emphasize the function of the maximum value, or overemphasize the role of the average. For this reason, this paper introduces a re-evaluation method based on the first-order fuzzy comprehensive evaluation function, that is, the second-order fuzzy comprehensive evaluation method.

The composition formula of the so-called second-order fuzzy comprehensive evaluation function $\mathrm{B}^{\prime}$ is as follows:

$$
\begin{aligned}
& B^{\prime}=f\left(B, B_{I}, B_{I I}, B_{I I I}\right)=c_{1} B+c_{2} B_{I}+c_{3} B_{I I}+c_{4} B_{I I I} \\
& B^{\prime}=c_{1} B+c_{2} B_{I}+c_{3} B_{I I}+c_{4} B_{I I I}=\left(b_{1}^{\prime}, b_{2}^{\prime}, \ldots, b_{m}^{\prime}\right)=\left(b_{j}^{\prime}\right) 1^{*} m
\end{aligned}
$$

In the above formula: $b_{j}^{\prime}=\left(c_{1} b+c_{2} b_{j}^{I}+c_{3} b_{j}^{I I}+c_{4} b_{j}^{I I I}\right)(j=1,2, \cdots, \mathrm{m})$;

$\mathrm{c}_{\mathrm{i}}-$ constant coefficient , $\mathrm{c}_{\mathrm{i}}>0(\mathrm{i}=1,2,3,4)$;

$b_{j}$ - The degree to which the sample belongs to the $\mathrm{j}$ grade water assessed by the type I fuzzy comprehensive evaluation function BI;

Remainder analogies.

There is no exact method to determine the coefficient of $c_{i}$ in this model. The analytic hierarchy process is used to calculate the $\mathrm{c}_{\mathrm{i}}$. The obtained two-stage fuzzy comprehensive evaluation method is called the improved two-stage fuzzy evaluation method.

The process of calculating the value of $c_{i}$ by AHP is as follows: by comparing the four factors of $\mathrm{B}, \mathrm{B}_{\mathrm{I}}, \mathrm{B}_{\mathrm{II}}, \mathrm{B}_{\mathrm{III}}$ with 1-9 scale method, the discriminant matrix can be obtained as follows: 


\begin{tabular}{|c|c|c|c|c|c|}
\hline & B & $B_{\text {I }}$ & $B_{\text {II }}$ & $B_{\text {III }}$ & W \\
\hline B & 1 & 0.2 & 0.142857143 & 3 & 0.0831 \\
\hline$B_{\text {I }}$ & 5 & 1 & 0.25 & 7 & 0.2640 \\
\hline \multirow{2}{*}{$B_{\text {II }}$} & 7 & 4 & 1 & 9 & 0.6116 \\
\hline \multirow{2}{*}{$B_{\text {III }}$} & 0.3333333 & 0.142857143 & 0.111111111 & 1 & 0.0414 \\
\hline \multirow{2}{*}{ Test } & \multicolumn{2}{|c|}{$\lambda$ max $=4.235$} & \multicolumn{3}{|c}{ RI $=0.89$} \\
\cline { 2 - 6 } & \multicolumn{2}{|c|}{ CI $=0.078$} & $0.088<0.1$ \\
\hline
\end{tabular}

So, the value of $c_{i}$ is: $c_{1}=0.0831 、 c_{2}=0.2640 、 c_{3}=0.6116 、 c_{4}=0.0414$.

\section{Results and discussion}

\subsection{Hydrochemical characteristics}

\subsubsection{Groundwater statistical analysis}

Descriptive statistical analysis of the hydrochemical parameters of groundwater is the basis of studying its characteristics and evolution law [9]. Through descriptive statistical analysis, the enrichment and variation of each chemical component in groundwater can be roughly understood. The results of the analysis are shown in Table 1.

Table 1. Descriptive analysis of hydrochemical parameters.

\begin{tabular}{|c|c|c|c|c|c|c|c|c|c|c|c|}
\hline Parameters & Min & Max & Average & SD & $\mathrm{CV}(\%)$ & Parameters & Min & Max & Average & SD & $\mathrm{CV}(\%)$ \\
\hline pH & 7.6 & 8.4 & 7.91 & 0.29 & 3.68 & $\mathrm{Fe}^{3+}$ & 0.06 & 3.16 & 1.01 & 1.09 & 108 \\
\hline $\mathrm{Ca}^{2+}$ & 48.1 & 255 & 111 & 65.0 & 58.8 & $\mathrm{Fe}^{2+}$ & $\mathbf{0}$ & 2.23 & 0.49 & 0.73 & 1508 \\
\hline $\mathbf{M g}^{2+}$ & 27.2 & 217 & 90.8 & 55.7 & 61.3 & $\mathrm{NO}_{2}^{-}$ & $\mathbf{0}$ & 0.29 & 0.04 & 0.08 & 227 \\
\hline $\mathbf{K}^{+}$ & $\mathbf{0}$ & 34.4 & 3.97 & 9.63 & 243 & $\mathrm{NO}_{3}^{-}$ & 0 & 93.6 & 10.9 & 27.1 & 249 \\
\hline $\mathbf{N a}^{+}$ & 9.73 & 254 & 67.6 & 79.9 & 118 & $\mathbf{P}_{2} \mathbf{O}_{5}$ & o & 0.46 & 0.13 & 0.15 & 109 \\
\hline $\mathrm{Cl}^{-}$ & 0 & 257 & 88.5 & 97.8 & 111 & $\mathrm{SiO}_{2}$ & 0.54 & 15.4 & 10.6 & 4.48 & 42.4 \\
\hline $\mathrm{SO}_{4}^{2-}$ & o & 127 & 33.8 & 35.6 & 105 & $\mathbf{F}^{-}$ & 0.11 & 3.64 & 0.79 & 0.93 & 118 \\
\hline $\mathrm{CO}_{3}^{2-}$ & 0 & 27.4 & 3.48 & 8.59 & 247 & TDS & 326 & 1228 & 721 & 324 & 44.9 \\
\hline $\mathrm{HCO}_{3}^{-}$ & 152 & 1070 & 4137 & 262 & 63.3 & TH & 130 & 803 & 364 & 210 & 57.7 \\
\hline $\mathbf{N H}_{4}{ }^{+}$ & $\mathbf{0}$ & 2.62 & 0.51 & 0.78 & 155 & TA & 70 & 491 & 193 & 119 & 61.8 \\
\hline
\end{tabular}

$\mathrm{pH}$ in standard units, the other ions are in $\mathrm{mg} / \mathrm{L}$, TH total hardness in $\mathrm{mg} / \mathrm{L}$, TDS total dissolved solids in $\mathrm{mg} / \mathrm{L}$, TA total alkalinity in $\mathrm{mg} / \mathrm{L}, \mathrm{SD}$ standard deviation, $\mathrm{CV}$ coefficient variation.

It can be seen from Table 1 that the $\mathrm{pH}$ is 7.6-8.4, which makes water weak alkaline. Salinity ranges between $326-1230 \mathrm{mg} / \mathrm{L}$ and the mean is $721 \mathrm{mg} / \mathrm{L}$, and some of the water samples exceed the drinking water standard. The value of total hardness is $130-803 \mathrm{mg} / \mathrm{L}$. The coefficient variations (CV) of those parameters range from $3.68 \%$ to $249 \%$. The $\mathrm{pH}$ has a smallest coefficient variations of $3.68 \%$, which indicates that its spatial variability is 
small. While $\mathrm{CV}$ values for $\mathrm{Ca}^{2+} 、 \mathrm{Mg}^{2+} 、 \mathrm{HCO}_{3}{ }^{-} 、 \mathrm{SiO}_{2} 、 \mathrm{TDS} 、 \mathrm{TH} 、 \mathrm{TA}$ are medium, $30 \%$ to $100 \%$, the other ions $\mathrm{CV}$ are $>100 \%$, reflecting the strong spatial variability.

\subsubsection{Correlation matrix}

Correlation analysis can reveal the similarity of groundwater hydrochemical parameters and the consistency and difference of the groundwater source. The correlation analysis method is used to analyze the contents of chemical components, salinity, precipitation and buried depth of the groundwater table. The results show that the relationship between them is very complicated, and the results are shown in Table 2.

Table 2. Pearson correlation coefficients of groundwater parameters

\begin{tabular}{|c|c|c|c|c|c|c|c|c|c|c|c|c|}
\hline & $\begin{array}{c}\text { Current } \\
\text { year } \\
\text { rainfall }\end{array}$ & $\begin{array}{c}\text { Groundw- } \\
\text { ater level } \\
\text { depth }\end{array}$ & $\mathrm{Ca}^{2+}$ & $\mathbf{M g}^{2+}$ & $\mathbf{K}^{+}$ & $\mathbf{N a}^{+}$ & $\mathrm{Cl}^{-}$ & $\mathrm{SO}_{4}^{2-}$ & $\mathrm{CO}_{3}{ }^{2-}$ & $\mathrm{HCO}_{3}^{-}$ & TDS & TH \\
\hline $\begin{array}{l}\text { Current } \\
\text { year } \\
\text { rainfall }\end{array}$ & 1 & & & & & & & & & & & \\
\hline $\begin{array}{l}\text { Groundw- } \\
\text { ater level } \\
\text { depth }\end{array}$ & -0.46 & 1 & & & & & & & & & & \\
\hline $\mathrm{Ca}^{2+}$ & -0.44 & 0.56 & 1 & & & & & & & & & \\
\hline $\mathrm{Mg}^{2+}$ & -0.49 & 0.83 & 0.51 & 1 & & & & & & & & \\
\hline $\mathbf{K}^{+}$ & -0.27 & -0.06 & -0.20 & -0.04 & 1 & & & & & & & \\
\hline $\mathbf{N a}^{+}$ & -0.7 & 0.70 & 0.85 & 0.59 & -0.14 & 1 & & & & & & \\
\hline $\mathrm{Cl}^{-}$ & -0.39 & 0.45 & 0.75 & 0.39 & 0.002 & 0.75 & 1 & & & & & \\
\hline $\mathrm{SO}_{4}{ }^{2-}$ & 0.2 & -0.27 & 0.16 & -0.4 & 0.07 & 0.08 & 0.26 & 1 & & & & \\
\hline $\mathrm{CO}_{3}{ }^{2-}$ & -0.18 & -0.04 & 0.15 & 0.017 & 0.02 & 0.11 & 0.11 & -0.13 & 1 & & & \\
\hline $\mathrm{HCO}_{3}^{-}$ & -0.04 & 0.55 & 0.76 & 0.58 & -0.23 & 0.59 & 0.7 & -0.1 & -0.04 & 1 & & \\
\hline TDS & 0.54 & 0.92 & 0.7 & 0.8 & -0.2 & 0.81 & 0.42 & -0.27 & -0.06 & 0.54 & 1 & \\
\hline TH & 0.45 & 0.79 & 0.61 & 0.77 & -0.18 & 0.75 & 0.43 & -0.34 & 0.36 & 0.46 & 0.86 & 1 \\
\hline
\end{tabular}

It can be seen from Table 2 that $\mathrm{Ca}^{2+} 、 \mathrm{Mg}^{2+} 、 \mathrm{Na}^{+}$, the total hardness has a good correlation with TDS. Because when the evaporation concentration is greater, the salinity increases. During the evaporation process, the insoluble salt precipitates continuously, leaving the high solubility $\mathrm{NaCl}$, therefore, the concentrations of $\mathrm{Na}$ and $\mathrm{Cl}^{-}$in groundwater with high salinity are higher.

\subsubsection{Groundwater chemical type}

The chemical type of groundwater in the study area is mainly $\mathrm{HCO}_{3}-\mathrm{Ca}$ type. From southeast to northwest, the hydrochemical type change from $\mathrm{Ca} \rightarrow \mathrm{Ca} \bullet \mathrm{Na} \rightarrow \mathrm{Ca} \bullet \mathrm{Na} \cdot \mathrm{Mg} \rightarrow$ $\mathrm{Na} \bullet \mathrm{Mg} \rightarrow \mathrm{Na}$. The variation trend of groundwater hydrochemical type is in good agreement with the variation of regional topography.

\subsection{Groundwater quality assessment}

The groundwater quality standard (GB/T14848-2017) [10] was used to evaluate the water quality by Two-stage Fuzzy Comprehensive Evaluation method. The evaluation indexes 
were ammonia nitrogen, iron, fluoride, chloride, nitrate, sulfate, TDS, the total hardness, and nitrite. The evaluation results are shown in Table 3.

It can be seen from Table 3 that the water quality of $50 \%$ of the water samples is within III type water, while the remaining $50 \%$ is $\mathrm{V}$ type water. Through the single factor analysis of each water sample, it is found that the serious exceeding of iron and manganese standard

Table 3.The results of groundwater quality assessment.

\begin{tabular}{lcccccc}
\hline & $\begin{array}{c}\text { Water } \\
\text { quality } \\
\text { Grade }\end{array}$ & \multicolumn{5}{c}{ Maximum membership degree } \\
\cline { 3 - 7 } & & B & BI & BII & BIII & B' \\
\hline 1 & V & 0.6123 & 0.5724 & 0.5220 & 0 & 0.5437 \\
2 & II & 0.6822 & 0.5123 & 0.5897 & 0 & 0.5639 \\
3 & I & 0.4211 & 0.6174 & 0.3516 & 0 & 0.3869 \\
4 & III & 0.3609 & 0.3743 & 0.3737 & 0 & 0.3715 \\
5 & V & 0.6095 & 0.4748 & 0.4402 & 0 & 0.4653 \\
6 & V & 0.7946 & 0.7783 & 0.6487 & 0 & 0.6977 \\
7 & V & 0.5001 & 0.3798 & 0.3784 & 0 & 0.3803 \\
8 & I & 0.3882 & 0.4710 & 0.3047 & 0 & 0.3577 \\
9 & V & 0.5263 & 0.4227 & 0.3963 & 0 & 0.3948 \\
10 & V & 0.6433 & 0.5078 & 0.4850 & 0 & 0.5059 \\
11 & II & 0.3554 & 0.3960 & 0.3629 & 0 & 0.3302 \\
12 & I & 0.3741 & 0.5090 & 0.3680 & 0 & 0.3985 \\
\hline
\end{tabular}

It can be seen from Table 3 that the water quality of $50 \%$ of the water samples is within III type water, while the remaining $50 \%$ is V type water. Through the single factor analysis of each water sample, it is found that the serious exceeding of iron and manganese standard results in poor water quality, which is influenced by the primary geological conditions. The water in the study area can be treated to drinking water standards.

\section{Conclusion}

In this study, by analyzing the chemical characteristics of groundwater in Shuangliao City, it is shown that the dominant cation is $\mathrm{Ca}^{2+}$ and the dominant anion is $\mathrm{HCO}_{3}^{-}$. The results of water quality evaluation show that some of the groundwater quality in the study area is poor, which are affected by the primary geological conditions and human activities.

\section{References}

1. Zhang R., Basis of Hydrogeology . Geology Press, 2011

2. Chonh T., Kimj Y., Chois Y., Res. Geol., 49 (2), 113-20 (1999)

3. Frengstad B., Banks D., Siewers U, Sci. of the Tot. Environ., 277 (1-3), 101 (2001)

4. Pehlivan R., Yilmaz O., Hydrolog. Proces., 19 (20), 3947-71 (2005)

5. Baharm M., Rezam S., Environm. Earth Scien., 61 (5), 1065-73 (2010) 
6. Raon S., Raop S., Reddyg V., et al., Environm. Monit. \& Asses., 184 (8), 5189-214 (2012)

7. Ibnali Z., Frika Y., Ghzell L., et al., Arab. Jour. of Geosc., 10 (17) (2017)

8. Xiao, C. Monitoring and evaluation of water environment, Tsinghua Un. Press, (2008)

9. L. Jiang, P. Li, J. Guog., Jour. of geosc. and environment, 31(3), 285-290 (2009)

10. National Quality Standard for Groundwater in China. GB/T 14848-2017, China, (2017) 